\title{
HuangQi Decoction Ameliorates Renal Fibrosis via TGF- $\beta /$ Smad Signaling Pathway In Vivo and In Vitro
}

\author{
Jie Zhao ${ }^{\mathrm{a}}$ Li Wang ${ }^{\mathrm{b}}$ Ai-li Cao ${ }^{\mathrm{b}}$ Ming-Qian Jiang ${ }^{\mathrm{a}} \quad$ Xia Chen ${ }^{\mathrm{a}} \quad$ Yi Wang \\ Yun-man Wang ${ }^{a}$ Hao Wang ${ }^{a}$ Xue-Mei Zhang ${ }^{c}$ Wen Penga,b \\ aDepartment of Nephrology, Putuo Hospital, Shanghai University of Traditional Chinese Medicine, \\ 'Laboratory of Renal Disease, Putuo Hospital, Shanghai University of Traditional Chinese Medicine, \\ 'Department of Pharmacology, School of Pharmacy, Fudan University, Shanghai, China
}

\section{Key Words}

HuangQi decoction • TGF- $\beta /$ Smad signaling pathway • UUO model • Renal interstitial fibrosis

\begin{abstract}
Objective: Traditional Chinese Medicine compound HuangQi decoction is widely used in clinical treatment of chronic kidney disease, but its role on renal interstitial fibrosis and the underlying mechanism remains unclear. The aim of this study is to investigate the effect of HuangQi decoction on renal interstitial fibrosis and its association with the TGF- $\beta / S m a d$ signaling pathway. Methods: A total of $120 \mathrm{C} 57 / \mathrm{BL}$ mice were randomly divided into six groups: sham group, sham plus high-dose HuangQi decoction $(1.08 \mathrm{~g} / \mathrm{kg})$ group, unilateral ureteral obstruction (UUO) model group, and UUO model plus low to high doses of HuangQi decoction $(0.12 \mathrm{~g} / \mathrm{kg}, 0.36 \mathrm{~g} / \mathrm{kg}$ and $1.08 \mathrm{~g} / \mathrm{kg}$ respectively) groups. Animals were sacrificed 14 days after the administration and ipsilateral kidney tissue was sampled for pathologic examinations. Immunohistochemistry, PCR and western blot were used to detect the expressions of related molecules in the TGF- $\beta /$ Smad signaling pathway. TGF- $\beta 1$ was used in in vitro experiments to induce human kidney proximal tubule epithelial cells (HK2). Results: HuangQi decoction improved ipsilateral kidney fibrosis in UUO mice and downregulated the expressions of TGF- $\beta 1$, T $\beta R I$, T $\beta$ RII, Smad4, Smad2/3, P-Smad2/3, $\alpha$-SMA, collagen type I, III and IV in a dose-dependent manner while upregulated the expression of Smad7 in the same fashion. Similar results were found in in vitro studies. Conclusion: The protective effect of HuangQi decoction for unilateral ureteral obstruction kidney damage in mice was mediated by downregulating the TGF- $\beta /$ Smad signaling pathway.
\end{abstract}




\section{Cellular Physiology Cell Physiol Biochem 2016;38:1761-1774 \\ \begin{tabular}{ll|l} 
and Biochemistry & $\begin{array}{l}\text { DOI: 10.1159/000443115 } \\
\text { Published online: May 09, 2016 }\end{array}$ & $\begin{array}{l}\text { ( ) 2016 The Author(s). Published by S. Karger AG, Basel } \\
\text { www.karger.com/cpb }\end{array}$ \\
\hline
\end{tabular} \\ Zhao et al.: HuangQi Decoction Ameliorates Renal Fibrosis}

\section{Introduction}

Renal interstitial fibrosis is a common pathway of chronic kidney disease up until end stage renal disease (ESRD) [1-3], which is a key indicator in renal prognosis reflecting the severity of the renal function deterioration. Tubular epithelial-mesenchymal transition (EMT) plays a key role in the development and progression of renal interstitial fibrosis [4]. When EMT is activated, the kidney fibroblasts could transdifferentiate into myofibroblasts (MFBs) that express $\alpha$-SMA and fibronectin and secrete excess extracellular matrix (ECM), the deposition of which within the tissue would eventually cause fibrosis. Transforming growth factor- $\beta 1$ (TGF- $\beta 1$ ) is currently the strongest known fibrogenic factor, which can induce EMT activation in renal tubular epithelial cells, promote the synthesis of extracellular matrix components and inhibiting its degradation; On the other hand, it could stimulate the differentiation of tubular epithelial cells into MFBs, and thus play an important role in the pathogenesis of renal interstitial fibrosis [5]. Although not reversible at the late stage, renal interstitial fibrosis, which may have great significance in the prognosis of the disease, can be ameliorated and renal function could be improved provided with early and timely diagnosis and treatment.

Chinese medicine believes that "spleen-kidney deficiency" is an internal condition and key factor in the development of renal interstitial fibrosis. Therefore, "tonifying the spleen and the kidney" is the main principle of the ancient Chinese physicians in the treatment of renal interstitial fibrosis, and HuangQi decoction is one of the most classic recipes in the clinical treatment of chronic kidney disease. HuangQi decoction was first recorded in Yang shiying's Renzhai Zhizhi Fang Volume 17 dating back to Northern Song Dynasty. The whole prescription consists of 7 kinds of Chinese medicine including Radix astragali, Wolfiporia extensa, Fructus trichosanthis, Radix ophiopogonis, Shizandra, Liquoric root, and Radix rehmanniae. HuangQi decoction is widely used in Traditional Chinese Medicine (TCM) practices due to its satisfactory efficacy, and although our published study has showed that the compound is a promising candidate for renal interstitial fibrosis [6], the mechanism of action still need to be further explored. In this study, we investigated the effect of HuangQi decoction in three doses, from low to high, on renal interstitial fibrosis in mice models with unilateral ureteral obstruction and its association with the TGF- $\beta$ /Smad signaling pathway. In addition, we induced human kidney proximal tubule epithelial cells (HK2) in vitro with TGF- $\beta 1$ to explore the mechanism of action of HuangQi decoction for interstitial fibrosis.

\section{Materials and Methods}

\section{Drugs and reagents}

All crudes of HuangQi decoction drugs were purchased from Shanghai Hua Yu Chinese Herbs Co., LTD. The gradient of the decoction consisted of $2 \mathrm{~kg}$ of Radix astragali (lot No. H2013031806), $2 \mathrm{~kg}$ of Wolfiporia extensa (lot No. H2012082001), 2 kg of Fructus trichosanthis (lot No. H2011011706), 2 kg of Radix ophiopogonis (lot No. H2012101604), 1 kg of Shizandra (lot No. H2013050303), $1 \mathrm{~kg}$ of Liquoric root (lot No. H2013052901), and $3 \mathrm{~kg}$ of Radix rehmanniae (lot No. H2012091801).

Antibodies to TGF- $\beta 1$, T $\beta$ RI, T $\beta R I I$, Smad4, $\alpha$-SMA, collagen I, III and IV were purchased from Abcam (Cambridge, MA, USA); Smad7 was purchased from R\&D Systems (Minneapolis, USA); Smad2/3, p-Smad2/3, fibronectin, $\beta$-actin and GAPDH, as well as goat anti-rabbit and goat anti-mouse antibodies were purchased from Cell Signaling Technology (Danvers, MA, USA). BCA protein quantification kit was purchased from Pierce (Rockford, IL, USA). ECL developing solution was purchased from Billerica (MA, USA).

The real-time quantitative PCR kit was purchased from Tiangen Biochemical Technology (Beijing, China), including RNeasy Mini Kit (QIAGEN, Valencia, CA), AMV First Strand cDNA Synthesis kit (QIAGEN, Valencia, CA) and SYBR green PCR master mix (QIAGEN, Valencia, CA). The primers were synthesized by Sangon Biotech Co. Ltd. (Shanghai, China). 


\section{Cellular Physiology Cell Physiol Biochem 2016;38:1761-1774 \begin{tabular}{l|l|l}
\cline { 2 - 3 } DOI: 10.1159/000443115 & (c) 2016 The Author(s). Published by S. Karger AG, Basel
\end{tabular} and Biochemistry Published online: May 09, 2016 www.karger.com/cpb}

Zhao et al.: HuangQi Decoction Ameliorates Renal Fibrosis

Animals and modeling

Animal experiments were approved by the ethics committee of Putuo Hospital, Shanghai University of Traditional Chinese Medicine. A total of 120 male C57/BL mice (body weight $18 \pm 2 \mathrm{~g}$ ) purchased from Shanghai Sippr-BK experimental animal Co., Ltd. with SPF-class breeding. After one week of adaptive feeding, mice were randomly divided into six groups. The selective doses of HuangQi decoction for animal study were calculated basing on the human optimal equivalent dose of $12 \mathrm{~g}$ raw herbs. A total amount of $1.0 \mathrm{~g}$ of extract powder that was about $13.3 \%$ of the raw herb was obtained._Similar with our previous study, HuangQi decoction at doses of $0.12,0.36$, and $1.08 \mathrm{mg} / \mathrm{kg}$ (dilutes with $0.5 \%$ sodium carboxymethyl cellulose) were chosen [6]._Mice in each group ingested the suspensions by gavage for 14 days after completion of modeling. Pure sham group and model group were given $0.5 \%$ sodium carboxymethyl cellulose. Mice were fasted the day before modeling. Anesthesia was done by intraperitoneal injection of $3 \%$ sodium pentobarbital, an incision on the left side of the abdomen was made to expose and dissect the left ureter, which was then ligated with 4-0 silk. The remnant middle ureter was sheared off. The sham group only underwent laparotomy and exposure of the left ureter. Blood samples and left kidney specimens were taken. The kidney specimen was cut open sagittally, half of which was fixed in $10 \%$ formalin, and the remaining half was stored at $-80^{\circ} \mathrm{C}$.

\section{Cell treatment}

HK2 cells were the courtesy of Dr. Zhang Xuemei from the School of Pharmacy, Fudan University. HK2 cells were cultured using complete RPMI 1640 medium (Cornning, USA) containing 10\% heat-inactivated fetal bovine serum (Gibco, USA). Cells were incubated in at $37^{\circ} \mathrm{C}$ with $5 \%$ carbon dioxide. HK2 cells in the $\log$ phase of growth was taken and digested by $0.25 \%$ trypsin-EDTA (Sigma-Aldrich) before mixing with the culture medium into cell suspension (concentration of about $4 \times 10^{4} / \mathrm{ml}$ ), which was then seeded in 96-well plates with $100 \mu \mathrm{l}$ for each well. After 12 hours the culture medium was aspirated before HuangQi decoctions in concentration gradient of $0,1,3,10,30,100,300,1000,3000$ and $10000 \mu \mathrm{g} / \mathrm{ml}$ were added. After 24 hours, the drug solution was discarded before CCK8 was added. The cells were then cultured for 1-4 hours, the absorbance at $450 \mathrm{~nm}$ was measured using a microplate reader. The HK2 cells were pretreated with HuangQi decoction at concentrations of 100,300 and $1000 \mu \mathrm{g} / \mathrm{ml}$ for $30 \mathrm{~min}$, and then TGF- $\beta 1$ at $2.5 \mathrm{ng} / \mathrm{ml}$ was added. After treatment with HuangQi decoction for $24 \mathrm{~h}$, protein expression was measured. Briefly, the samples were lysed with D-hanks ( 1 ml lysate was added to every $10 \mu \mathrm{PMSF}$ ) by sonication on ice. The supernatant was collected after centrifugation at $12,000 \mathrm{rpm}$ at $4{ }^{\circ} \mathrm{C}$ for $5 \mathrm{~min}$. Protein quantification was determined by BCA kits instructions.

\section{Histology and immunohistochemistry}

The kidney tissue was fixed in 10\% neutral formalin. After embedded in paraffin, sections were stained with H\&E staining and Masson's Trichrome staining. The assessment of tissue injury in the obstructed kidney after H\&E staining was in accordance with the scoring criteria described by Debelle et al. [7] with a slight alteration: A total of 10 unrepeated cortical areas were randomly selected (observed under 400x light microscope), the renal interstitial injury was assessed according to the 4 parameters and 4 grades (Table 1). Kidney injury after ureter obstruction under Masson's Trichrome staining was assessed by the method described by Mizuguchi et al. [8]. Blue staining was considered the positive signal: $0=$ normal; $1=$ lesion range from 0 to $25 \%$ of; 2 = lesion range from $25 \%$ to $50 \%$ (moderate damage); $3=$ lesion range more than $50 \%$ (severe damage) [9]. Immunohistochemical detection was done using the ABC method as previously reported [10,11]. Collagen IV (1: 100), P-Smad2/3 (1: 200) and $\alpha$-SMA (1: 100) were added after rinsing with PBS. The sheep anti-rabbit, goat anti-mouse secondary antibodies were then added. Image Pro Plus analysis software was used to calculate the mean optical density value.

Table 1. The scoring criteria of kidney tissue injury

\begin{tabular}{lllll}
\hline Score & Tubular atrophy & Tubular necrosis & Lymphocyte infiltration & Interstitial fibrosis \\
\hline 0 & None & None & None & None \\
1 & Mild, $<25 \%$ & Mild, $<25 \%$ & Mildly local & Mild, $<25 \%$ \\
2 & Moderate, $25 \%-50 \%$ & Moderate, $25 \%-50 \%$ & Mildly diffused or moderately local & Moderate, $25 \%-50 \%$ \\
3 & Moderate, $>50 \%$ & Moderate, $>50 \%$ & Severely diffused & Moderate, $>50 \%$ \\
\hline
\end{tabular}




\section{Cellular Physiology Cell Physiol Biochem 2016;38:1761-1774 \begin{tabular}{ll|l}
\cline { 2 - 3 } DOI: 10.1159/000443115 & () 2016 The Author(s). Published by S. Karger AG, Basel
\end{tabular} and Biochemistry Published online: May 09, 2016 www.karger.com/cpb \\ Zhao et al.: HuangQi Decoction Ameliorates Renal Fibrosis}

Table 2. Primers used for quantitative Real-time PCR

\begin{tabular}{|c|c|c|}
\hline Genes & Forward primer & Reverse primer \\
\hline TGF- $\beta 1$ & 5'-TGGCCAGATCCTGTCCAAAC-3' & 5'-GCGGGTGACCTCTTTAGCAT-3' \\
\hline$\alpha-S M A$ & 5'-GTTTCTCGCACGTCTCCTCT-3' & 5'-CAGGCAGTTCGTAGCTCTTC-3' \\
\hline $\mathrm{T} \beta \mathrm{RI}$ & 5'ACCGCCGATGAATATGGGTCT-3' & 5'-TGGCCTGTCTCGAGGAATTAG-3' \\
\hline $\mathrm{T} \beta \mathrm{RII}$ & 5'ACGTTCCCAAGTCGGATGTG-3' & 5'-TGTCGTTCTTCCTCCACACG-3' \\
\hline Smad-2 & 5'-TCGGCACACGGAGATTCTAAC-3' & 5'ACCAGAATGCAGGTTCCGAG-3' \\
\hline Smad-3 & 5'-CCGTGGAACTTACAAGGCGAC-3' & 5'-GGCAGCAAATTCCTGGTTGT-3' \\
\hline Smad-4 & 5'ATCAACGGAGACGTACAGCG-3' & 5'-TCCTCCCGAAGGATCCACAT-3' \\
\hline Smad-7 & 5'-TCTCAAACCAACTGGCTGTCC-3' & 5'AGAGCCTCCCCACGCGA-3' \\
\hline Collagen I & 5'-CATGGCCAAGAAGACATCCCT-3' & 5'-CATTGCATTGCACGTCATCG-3' \\
\hline Collagen III & 5'-AAGGCTGCAAGATGGATGCT-3' & 5'-GTGCTTACGTGGGACAGTCA-3' \\
\hline CollagenIV & 5'-ATGCACTCCAAGACTGCTCC-3' & 5'-TTTGCCTTTGCAGACACAGC-3' \\
\hline GAPDH & 5'-AGGAGAGTGTTTCCTCGTCC-3' & 5'-ATGGGCTTCCCGTTGATGAC-3' \\
\hline
\end{tabular}

Western blot analysis

Total protein extraction tissue: $1 \mathrm{mg}$ tissue was lysed in $1 \mathrm{~mL}$ of RIPA lysis buffer before centrifuged for $15 \mathrm{~min}$. The supernatant was then extracted to determine protein concentration. Tissue protein samples (sample volume of $20 \mu \mathrm{g}$ ) were separated by SDS-PAGE. After blocking with 5\% BSA, anti-TGF- $\beta 1$ (1: 1000 dilution), T $\beta R I$ (1: 1000 dilution), T $\beta$ RII (1: 1000 dilution), Smad 2/3 (1: 1000 dilution), p-Smad 2/3 (1: 1000 dilution), Smad 4 (1: 1000 dilution), $\alpha$-SMA (1: 1000 dilution), Smad 7 (1: 800 dilution), GAPDH (1: 1000 dilution), Collagen I/III (1: 5000 dilution) and Collagen IV (1: 1000 dilution) antibodies were added and incubated overnight at $4{ }^{\circ} \mathrm{C}$, the membrane was washed before secondary antibodies were added and incubated for $1 \mathrm{~h}$. TBST was used to wash the membrane and a solution of ECL developer was added. The gray value of the bands of interest was analyzed using Image J software.

\section{Real-time quantitative PCR}

Primers were designed with the Primer 5.0 software (Table 2). Total RNA was extracted with the RNeasy Mini Kit (QIAGEN, Valencia, CA) following the manufacturer's protocol. Briefly, $1 \mu \mathrm{g}$ of total RNA was reverse transcribed using the AMV First Strand cDNA Synthesis kit (QIAGEN, Valencia, CA) and synthesized complementary DNA was amplified by a standard PCR protocol using SYBR green PCR master mix (QIAGEN, Valencia, CA). Primers were synthesized from Sangon Biotech Co. Ltd. (Shanghai, China). The sequences of rat-specific primers for TGF- $\beta 1, \alpha$-SMA, T $\beta R I$, T $\beta R I$ I, Smad-2, Smad-3, 6, Smad-4, Smad-7,Collagen I, III, IVand GAPDH used in the study were enlisted in Table 2. Cycling conditions were: 15 min preincubation at $95^{\circ} \mathrm{C}, 10 \mathrm{sec}$ denaturation at $95^{\circ} \mathrm{C}, 31 \mathrm{sec}$ annealing at $58^{\circ} \mathrm{C}$ for 40 cycles using ViiA7 Standard 96 sequence detection system (Applied biosystems, USA). The PCR products from each primer pair were subjected to a melting curve analysis in order to confirm amplification specificity. Each reaction was amplified in triplicate and the threshold cycles $(\mathrm{Ct})$ were calculated using the $2^{-\Delta \Delta C t}$ method. Relative gene expression was normalized with GAPDH as an internal reference.

Statistical Analysis

The GraphPad Prism 5.0 software (San Diego, CA, USA) was used for statistical analysis. The $t$ test was used to compare the difference between two individual groups, and One-Way Analysis of Variance (ANOVA) was used to compare the difference among multiple groups; $P<0.05$ was considered statistically significant.

\section{Results}

HuangQi decoction alleviatded UUO matrix accumulation and improved renal interstitial damage in mice

After 14 days of unilateral ureteral obstruction, renal fibrosis on the obstructed side was significant. As shown in Fig. 1A, H\&E staining exhibited tubular atrophy with partial 


\section{Cellular Physiology Cell Physiol Biochem 2016;38:1761-1774 \begin{tabular}{c|l|l}
\hline DOI: 10.1159/000443115 & $\begin{array}{l}\text { ( ) 2016 The Author(s). Published by S. Karger AG, Basel } \\
\text { www.karger.com/cpb }\end{array}$ \\
and Biochemistry Published online: May 09, 2016 &
\end{tabular}

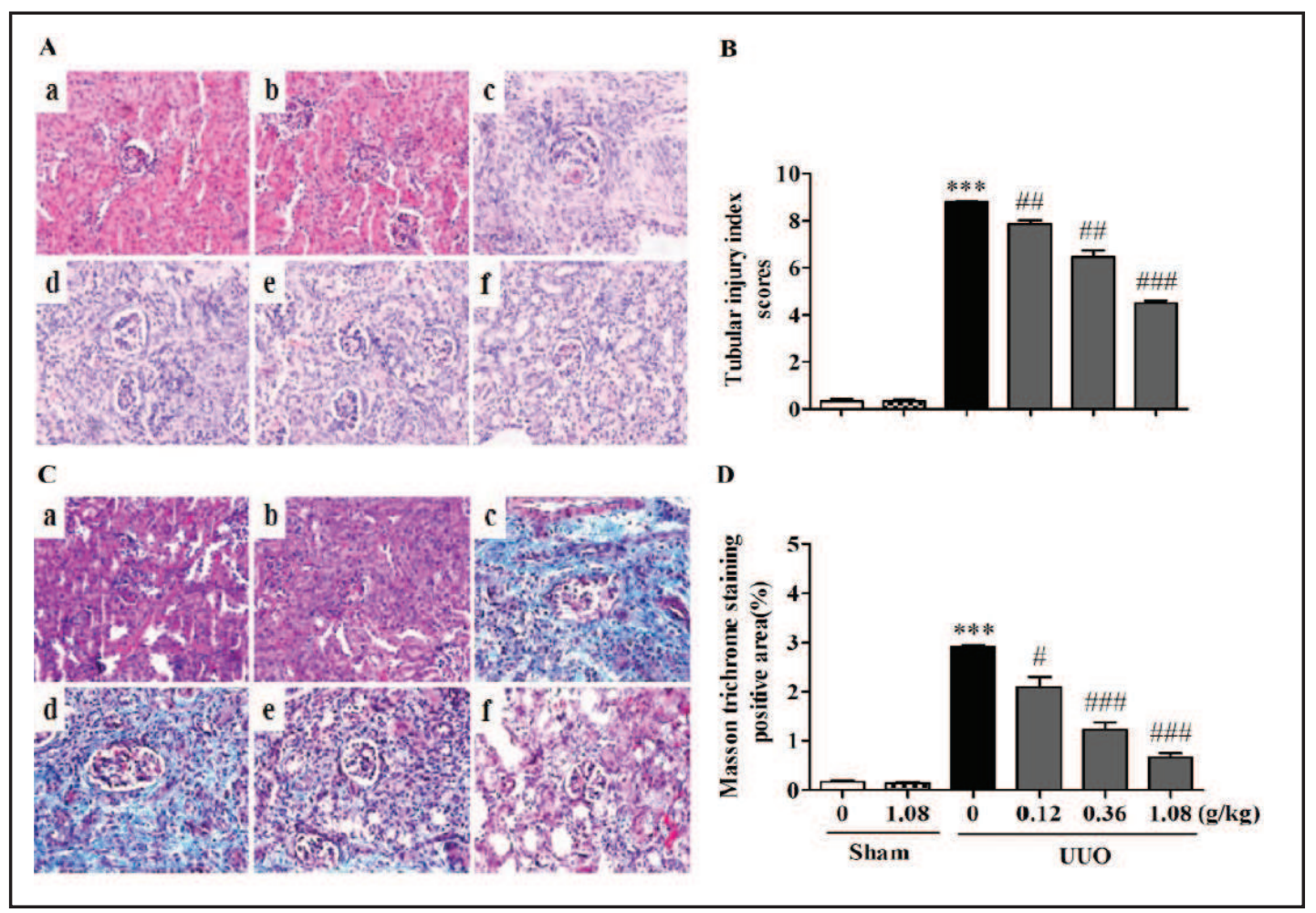

Fig. 1. Effect of HuangQi decoction on obstructed kidney tissue in UUO mice model. A. H\&E staining; B. Scoring criteria for renal interstitial damage; C. Masson's Trichrome staining; D. Masson's Trichrome staining with statistical analysis. a. Sham group; b. Sham group with high dose $(1.08 \mathrm{~g} / \mathrm{kg})$ of HuangQi decoction; c. UUO group; d. UUO group with low dose of HuangQi decoction $(0.12 \mathrm{~g} / \mathrm{kg})$ e. UUO group with medium dose of HuangQi decoction $(0.36 \mathrm{~g} / \mathrm{kg})$; f. UUO group with high dose of HuangQi decoction $(1.08 \mathrm{~g} / \mathrm{kg}) .{ }^{* * *} \mathrm{P}<$ 0.001 compared to Sham group; $\# \mathrm{P}<0.05$, \#\#P<0.01, \#\#\#P<0.001, compared to UUO group. $\mathrm{n}=12-15$.

necrosis, renal tubular collapse, structural damage, tubulointerstitial widening, fibrotic hyperplasia, inflammatory cell infiltration, and extracellular matrix deposition in UUO kidneys compared with those in sham-operative kidneys. Additionally, Masson's Trichrome staining showed large number of collagen fiber streaks staining blue with prominent collagen fiber hypertrophy in the obstructed kidney (Fig. 1C). However, treatment with HuangQi decoction led to less tubular epithelial cell degeneration and inflammatory cell infiltration compared with UUO group, and the collagen fiber streak (blue-stained area) in the treatment group also decreased in a dose-dependent manner significantly $(\mathrm{P}<0.05)$.

TGF- $\beta 1$ is considered the most critical factor in the pathogenesis of renal interstitial fibrosis and can be found in a variety of chronic kidney diseases [9, 12-14]. Collagen I, III and IV, $\alpha$-SMA and fibronectin were all markers for kidney myofibroblasts and extracellular matrix accumulation. They could be elevated in various types of chronic kidney damages [15-19] . In this study, we observed that the protein expression levels of TGF- $\beta 1$,Collagen I, III, IV and $\alpha$-SMA, fibronectin (Fig. 2) and expressions of TGF- $\beta 1$ mRNA (Fig. 3)in mice of the ureteral obstruction group were both significantly higher than the basal expression levels in the sham group $(P<0.05)$. After HuangQi decoction in low-to-high concentrations were given, mRNA levels and protein expression of TGF- $\beta 1$ in the treatment group decreased dose-dependently compared with those in the UUO model group $(P<0.05)$.

HuangQi decoction inhibited TGF- $\beta$-induced epithelial-mesenchymal transdifferentiation of HK2 cells

TGF- $\beta 1$ could activate the transdifferentiation ability of renal tubular epithelial cells, which, in turn, can lead to $\alpha$-SMA expression and synthesis of extracellular matrix such 


\section{Cellular Physiology Cell Physiol Biochem 2016;38:1761-1774 \begin{tabular}{ll|l} 
and Biochemistry & $\begin{array}{l}\text { DOI: 10.1159/000443115 } \\
\text { Published online: May 09, } 2016\end{array}$ & $\begin{array}{l}\text { O 2016 The Author(s). Published by S. Karger AG, Basel } \\
\text { www.karger.com/cpb }\end{array}$ \\
\cline { 1 - 2 }
\end{tabular} \\ Zhao et al.: HuangQi Decoction Ameliorates Renal Fibrosis}

Fig. 2. Effect of HuangQi decoction on expressions of TGF- $\beta 1$, Collagen I, III, IV, and $\alpha$-SMA detected by Western blot. A. Representative photographs showing protein expressions of TGF- $\beta 1$, Collagen I, III, IV, and $\alpha$-SMA. B-F. Statistical analyses versus A. ${ }^{* * *} \mathrm{P}<0.001$, compared to Sham group; $\# \mathrm{P}<0.05, \quad \# \# \mathrm{P}<0.01$, \#\#\#P<0.001, compared to UUO group. $\mathrm{n}=12-15$.

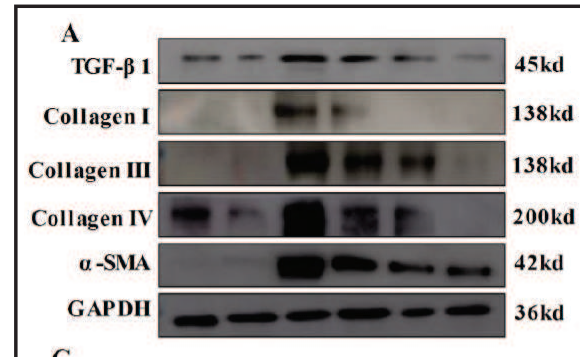

C

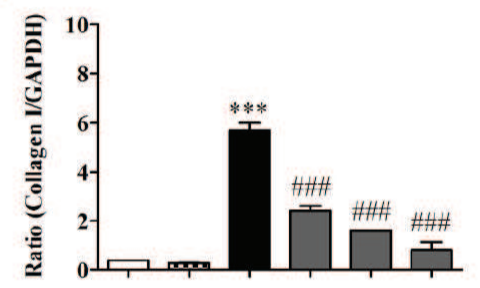

E

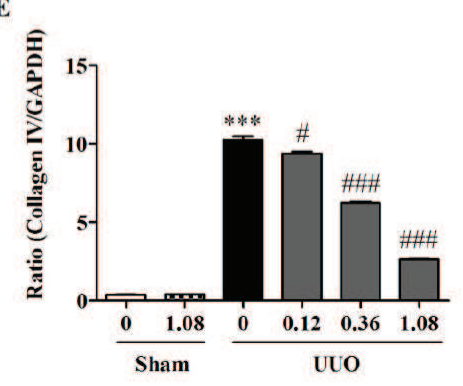

B

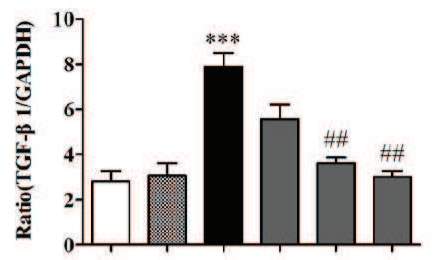

D

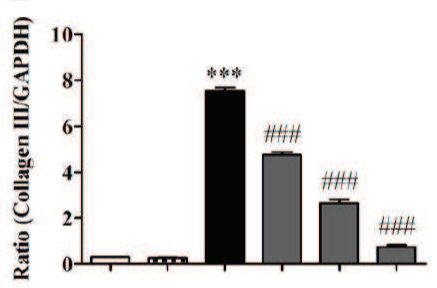

F

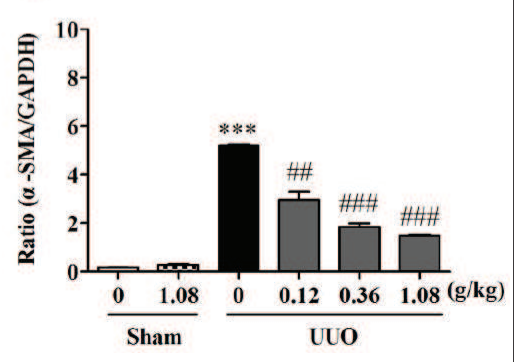

Fig. 3. Effect of HuangQi decoction on relative expressions of TGF- $\beta 1$, Collagen I, III, IV, $\alpha$-SMA and fibronectin mRNAs detected by PCR. A-F. Relative mRNA levels of TGF- $\beta 1$, Collagen I, III, IV, $\alpha$-SMA and fibronectin expression in kidneys. ${ }^{* * *} \mathrm{P}<0.001$, compared to sham group; $\# \mathrm{P}<0.05, \quad \# \# \mathrm{P}<0.01$, $\# \# \#$ P $<0.001$, compared to UUO group.

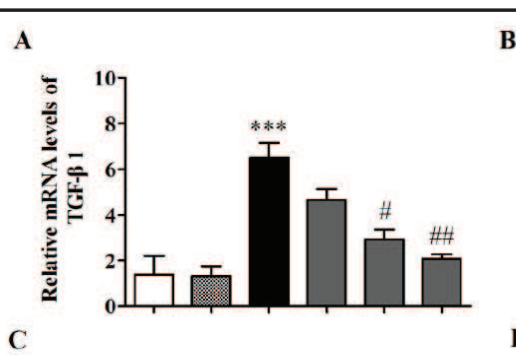

B
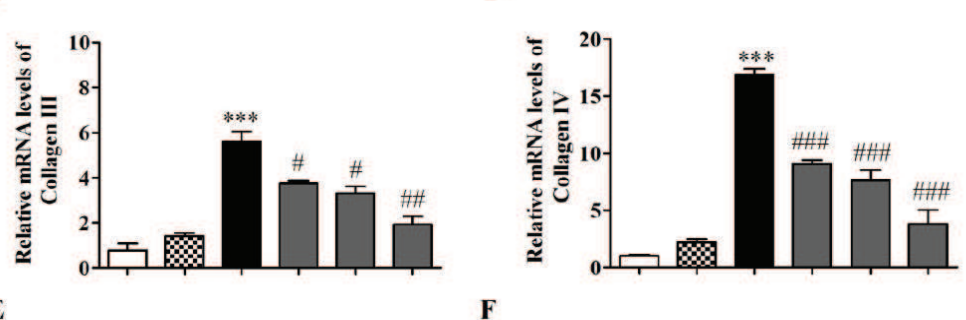
$\mathrm{n}=12-15$.
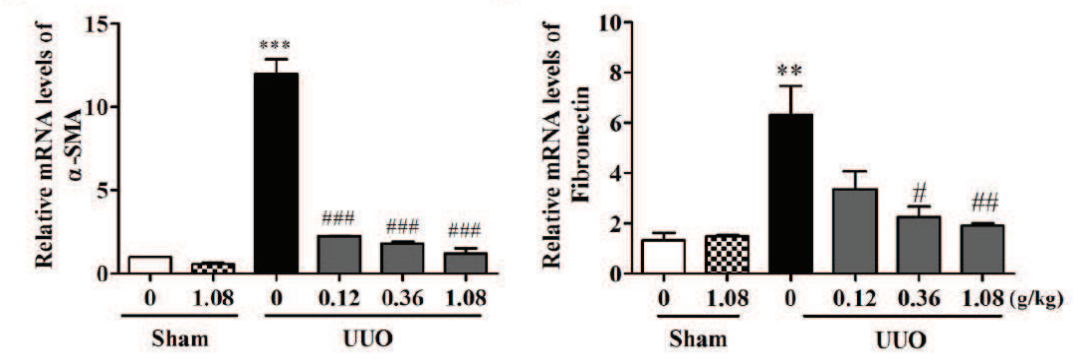

as Collagen I, III, IV and thus be involved in renal interstitial fibrosis. In our experiment, TGF- $\beta 1$ ( $2.5 \mathrm{ng} / \mathrm{ml})$ alone was used to treat HK2 cells, and western blot detected the protein 


\section{Cellular Physiology Cell Physiol Biochem 2016;38:1761-1774

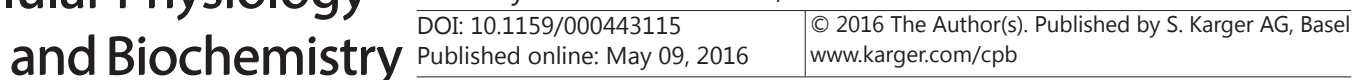

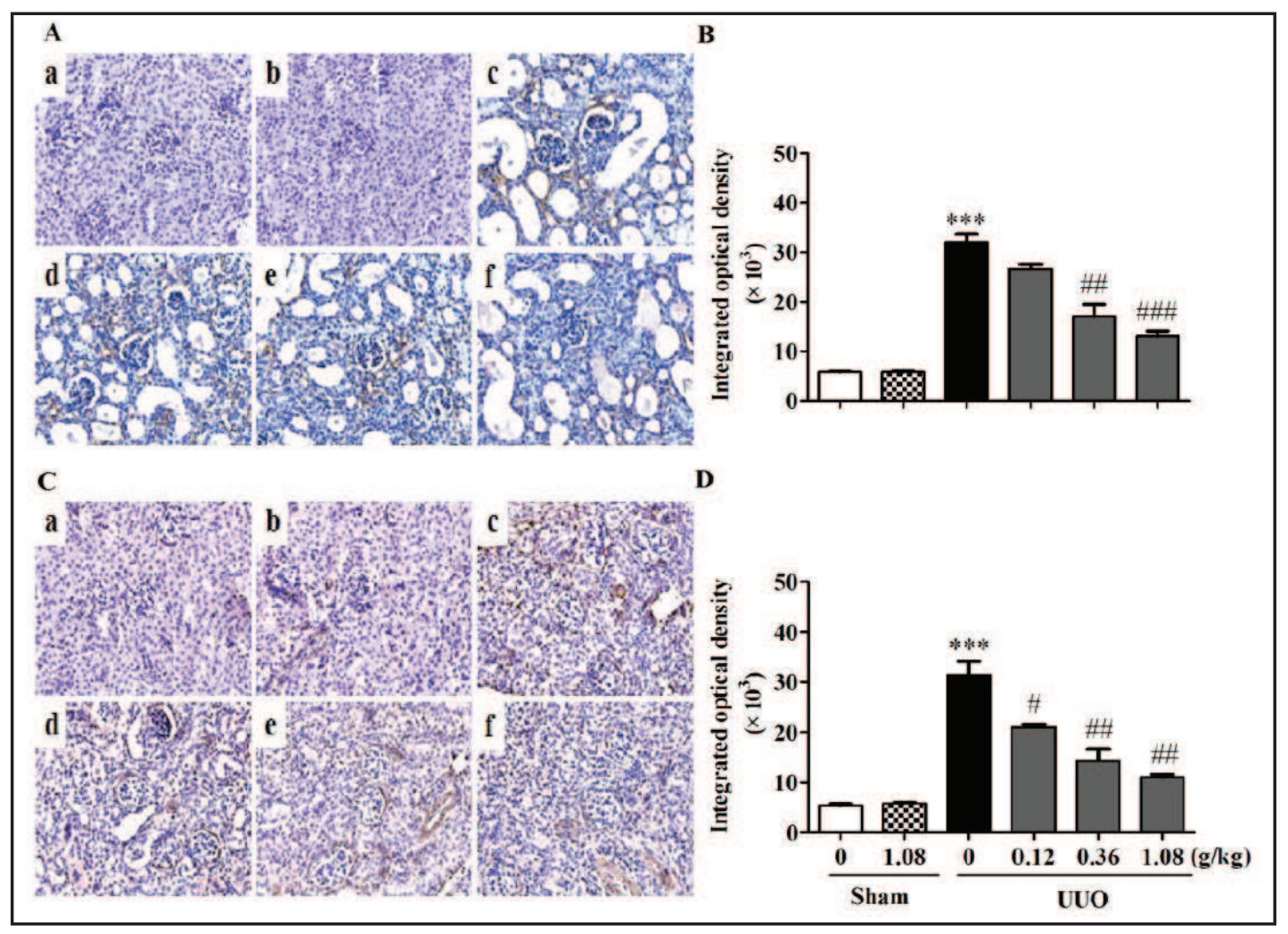

Fig. 4. Effect of HuangQi decoction on expressions of Collagen IV and $\alpha$-SMA in the left kidney of the mice detected by immunohistochemistry. A and C. Representative photomicrographs of Collagen IV and $\alpha$-SMA immunohistochemistry on kidney sections. B and D. Integrated optical density analysis of Collagen IV and $\alpha$-SMA expression from sections similar to those shown in A and C. ${ }^{* * *} \mathrm{P}<0.001$, compared to Sham group; $\# \mathrm{P}<0.05$, \#\#P<0.01, \#\#\#P<0.001, compared to UUO group. $\mathrm{n}=12-15$.

expressions of TGF- $\beta 1$, Collagen I, III, IV and $\alpha$-SMA increased significantly with TGF- $\beta 1$ treatment (Fig. 5A-F, $\mathrm{P}<0.05$ ), indicating the activation of EMT mechanism and accumulation of extracellular matrix. After HuangQi decoction of different concentrations $(100 \mu \mathrm{g} / \mathrm{ml}, 300$ $\mu \mathrm{g} / \mathrm{ml}$ and $1000 \mu \mathrm{g} / \mathrm{ml}$ ) were given, protein expressions TGF- $\beta 1$, Collagen I, III, IV and $\alpha$-SMA decreased in a concentration-dependent fashion $(P<0.05)$.

HuangQi decoction could downregulate the TGF- $\beta /$ Smad signaling pathway

Immunohistochemical detection showed increased P-Smad2/3 expression in the ipsilateral kidney of UUO mice model compared to the sham group (Fig. 6A-B), the difference was statistically significant $(P<0.05)$. After the treatments of HuangQi decoction in low-tohigh concentrations, expression of P-Smad2/3 decreased in a dose-dependent fashion. We also found the mRNA (Fig. 8A-E) and protein (Fig. 7A-F) expressions of T $\beta R I, T \beta R I I$, Smad2/3, P-Smad2/3 and Smad4 in mice of the UUO group were higher than the sham group. After the treatments of HuangQi decoction in low-to-high concentrations, expressions of T $\beta R I$, T $\beta R I I$, Smad2/3, P-Smad2/3 and Smad4 decreased in a dose-dependent fashion. The expressions of Smad7 mRNA (Fig. 8F) and protein (Fig. 7A, G) in UUO mice models were significantly lower than those in the sham group ( $\mathrm{P}<0.05)$, and Smad7 increased in a dose-dependent manner after HuangQi decoction of different concentrations were given. Western blot of in vitro experiments detected increased T $\beta R I, T \beta R I I, S m a d 2 / 3, P-S m a d 2 / 3$ and Smad4 levels after TGF- $\beta 1(2.5 \mathrm{ng} / \mathrm{ml})$ stimulation of HK2 cells (Fig. 9A-F, $P<0.05)$. This expression decreased after HuangQi decoction treatment in a concentration-dependent fashion. Meanwhile, the expression of Smad7 protein significantly decreased after stimulation (Fig. 9A, G, $P<0.05$ ), and increased dose-dependently after HuangQi decoction were given. 


\section{Cellular Physiology Cell Physiol Biochem 2016;38:1761-1774 \begin{tabular}{ll|l} 
DOI: 10.1159/000443115 & O 2016 The Author(s). Published by S. Karger AG, Basel \\
\hline
\end{tabular} and Biochemistry Published online: May 09, 2016 www.karger.com/cpb

Fig. 5. Effect of HuangQi decoction on expressions of TGF- $\beta 1$, Collagen I, III, IV, and $\alpha$-SMA in HK2 cells detected by Western blot. A. Representative photographs showing protein expressions of TGF- $\beta 1$, Collagen I, III, IV, and $\alpha$-SMA. B-F. Statistical analyses versus A. *** $<<0.001$, compared to Sham group; $\# \mathrm{P}<0.05$, $\# \# \mathrm{P}<0.01$, \#\#\#P<0.001, compared to UUO group, $n=3-5$.
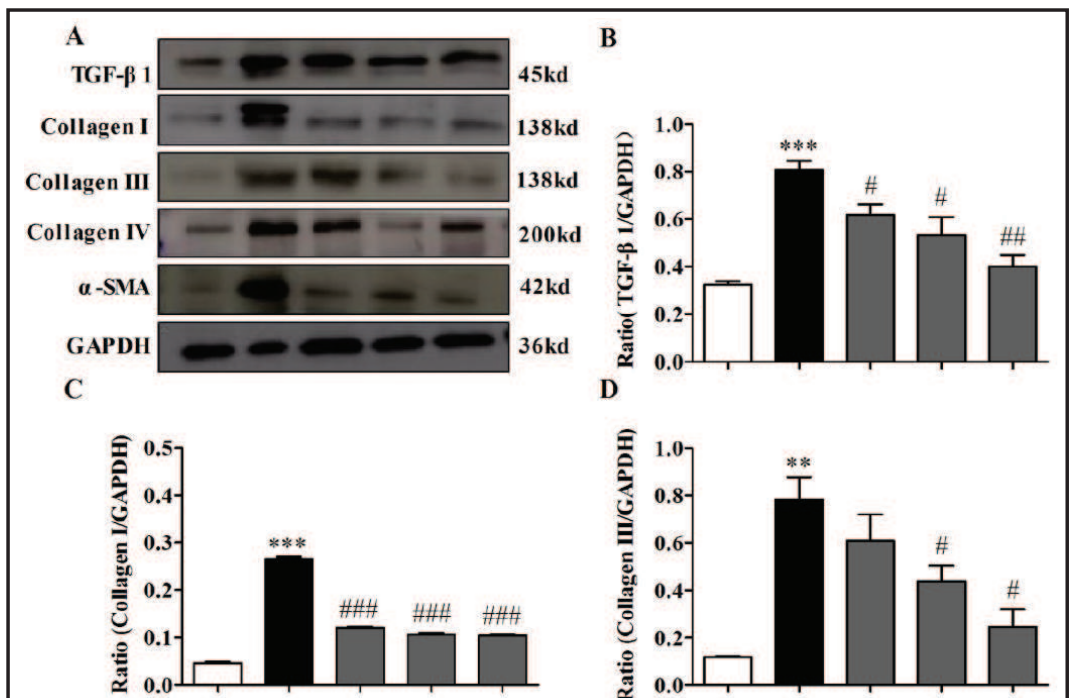

E
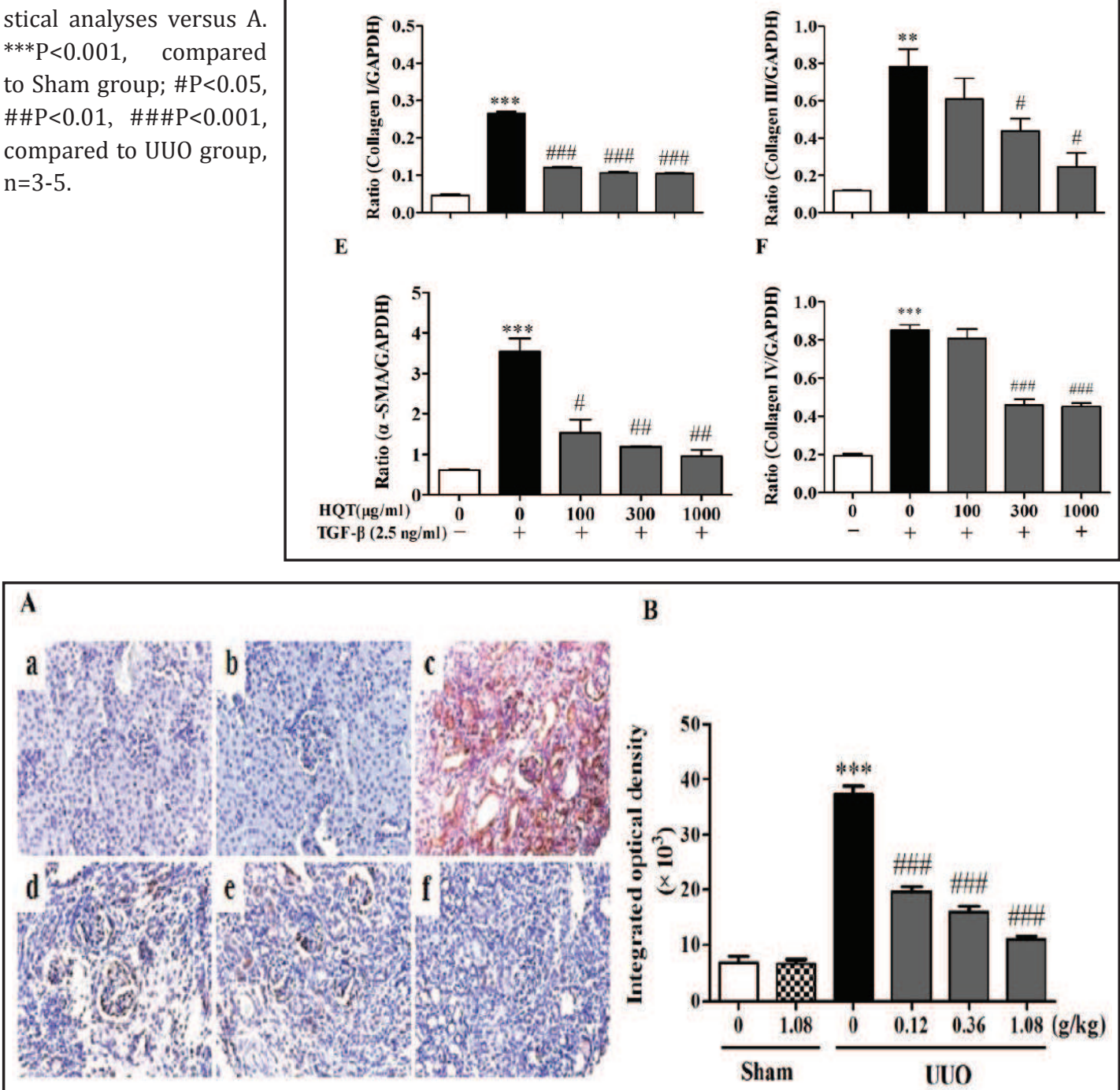

B

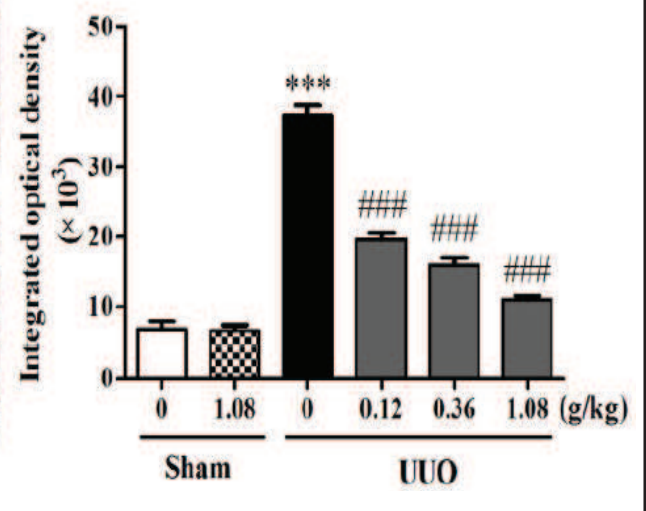

Fig. 6. Effect of HuangQi decoction on expressions of P-Smad2/3 detected by immunohistochemistry. A. Expression of $\mathrm{P}-\mathrm{Smad} 2 / 3$ in the left kidney; B Statistical analysis versus A. ${ }^{* * *} \mathrm{P}<0.001$, compared to Sham group; $\# \mathrm{P}<0.05, \# \# \mathrm{P}<0.01, \# \# \# \mathrm{P}<0.001$, compared to UUO group. $\mathrm{n}=3-5$.

\section{Discussion}

Modern pharmacological studies have demonstrated that each single drug in HuangQi decoction could be beneficial in chronic kidney disease. For instance, astragalus could alleviate macrophage infiltration tubular interstitial fibrosis in the renal tissue of a rat

\section{KARGER}




\section{Cellular Physiology Cell Physiol Biochem 2016;38:1761-1774 \begin{tabular}{cl|l} 
DOI: 10.1159/000443115 & $\begin{array}{l}\text { () 2016 The Author(s). Published by S. Karger AG, Basel } \\
\text { www.karger.com/cpb }\end{array}$
\end{tabular}

Fig. 7. Effect of HuangQi decoction on expressions of T $\beta R I$, TßRII, Smad2/3, $\mathrm{P}$ - S m a d 2 / 3 , Smad4 and Smad7 detected by Western blot. A. Protein expressions after treatment. B-G, statistical analyses. $* * * \mathrm{P}<0.001$, compared to Sham group, $\# \mathrm{P}<0.05$, \# \# $\mathrm{P}<0.01$, \# \# \# P $<0.001$, compared to UUO group. $n=3-5$.
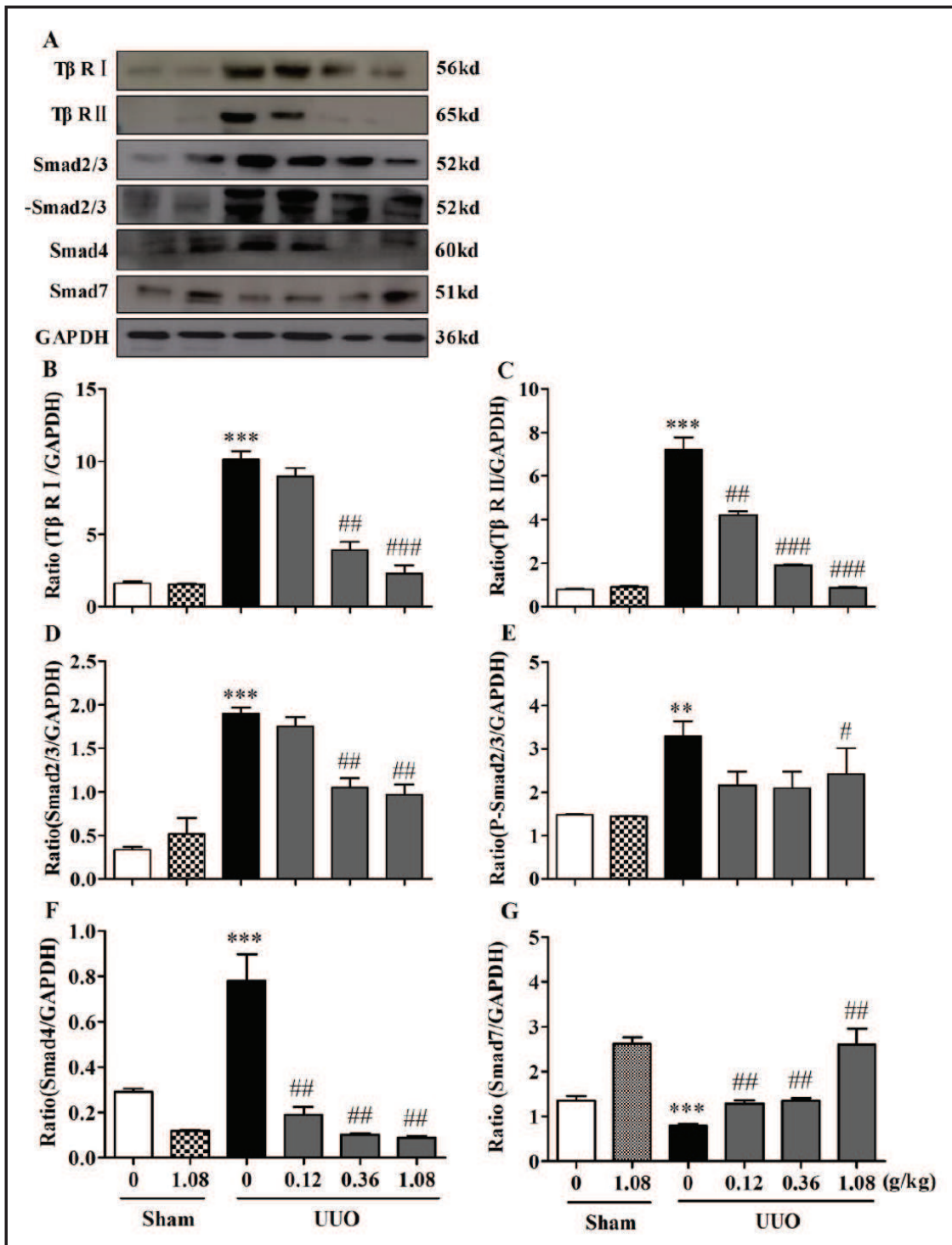

model, and thus delaying the process of chronic kidney disease [20]; By regulating TIMP-1, MMP and expression of TGF- $\beta 1$, it could improve the renal interstitial fibrosis in Adriamycininduced rat models [21]; Astragaloside could improve renal fibrosis in UUO rat models by downregulating TGF- $\beta /$ Smad and $w n t / \beta$-catenin signaling pathway in in vivo experiments [22-24]. Poria could slow down the progress of chronic kidney disease by the intervention on certain metabolic pathways (e.g. metabolism of adenine and amino acid) [25, 26]. Melon was proved to be able to improve myocardial fibrosis by regulating TGF- $\beta /$ Smad signaling pathway [27] and could thereby alleviate the cisplatin-induced kidney damage proved by in vitro and in vivo experiments [28]. The main monomer of Radix, ruscogenin, was found with an anti-fibrotic effect for diabetic nephropathy in rats [29], Schisandrin, which is rich in Chinese medicine Schisandra, could inhibit TGF- $\beta$ signaling pathway to achieve an anti-fibrotic effect as well $[30,31]$. Licorice could downregulate TGF- $\beta 1 /$ Smad signal transduction, and thus play a therapeutic role in the processes of interstitial fibrosis and glomerulosclerosis [32]. Meanwhile, Radix rehmanniae was proved to be able to alleviate hematuria and proteinuria associated with chronic glomerulonephritis [33], as well as bring improvement in diabetic nephropathy [34]. The present study demonstrated the role of HuangQi decoction in improving renal interstitial fibrosis, reducing extracellular matrix 


\section{Cellular Physiology Cell Physiol Biochem 2016;38:1761-1774 \begin{tabular}{ll|l}
\cline { 2 - 4 } DOI: 10.1159/000443115 & () 2016 The Author(s). Published by S. Karger AG, Basel
\end{tabular} and Biochemistry Published online: May 09, 2016 www.karger.com/cpb}

A

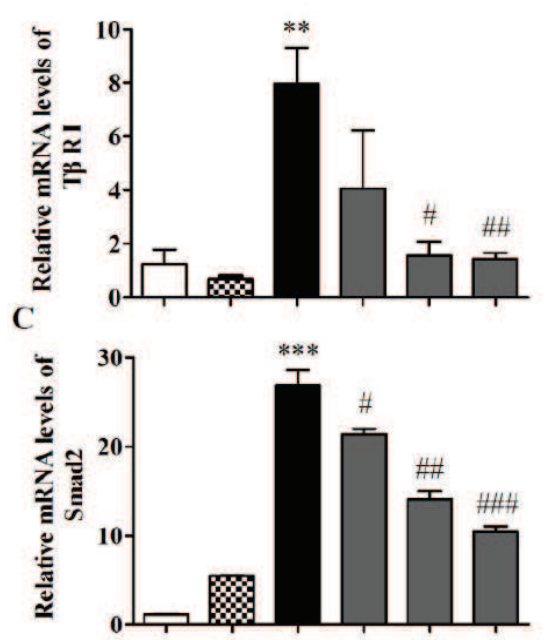

$\mathbf{E}$

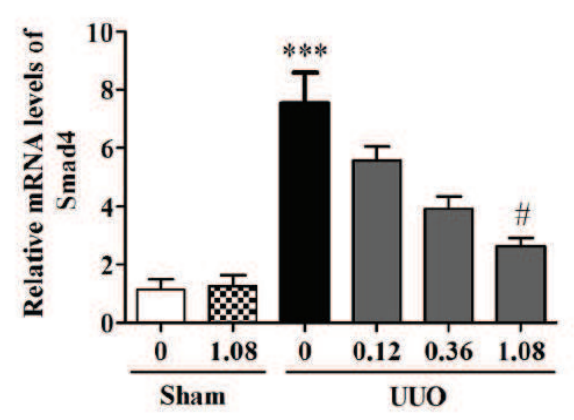

B

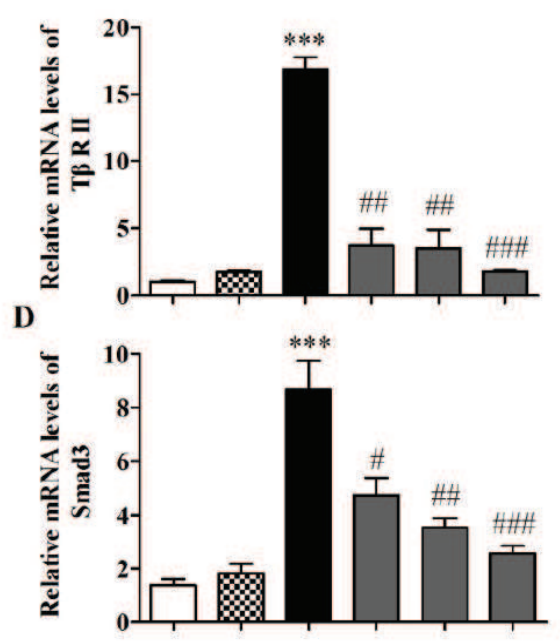

F

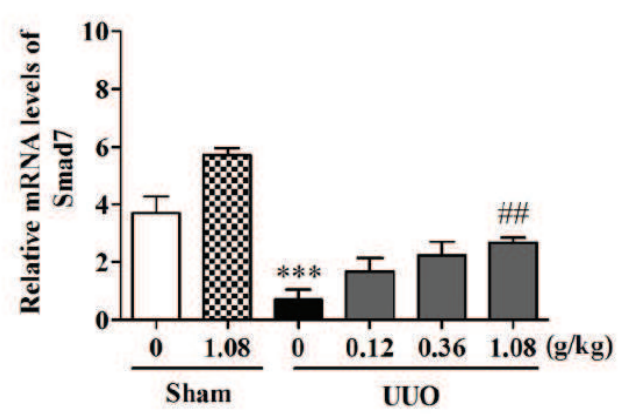

Fig. 8. Effect of HuangQi decoction on mRNA and protein expressions of T $\beta R I, T \beta R I I$, Smad2/3, P-Smad2/3, Smad4 and Smad7 detected by PCR. A-F. mRNA and protein expressions. ${ }^{* * *} \mathrm{P}<0.001$, compared to Sham group; $\# \mathrm{P}<0.05$, \#\#P<0.01, \#\#\#P<0.001, compared to UUO group. $\mathrm{n}=3-5$.

accumulation, and downregulating TGF- $\beta$ /Smad signaling pathway in unilateral ureteral obstruction mice models.

Renal interstitial fibrosis is a key process in the progression of chronic kidney disease to end-stage renal disease. Compared to glomerulosclerosis, interstitial fibrosis plays a more critical role in the consequence of nephron loss. TGF- $\beta 1$ is a pleiotropic fibrosis-inducing cytokine recognized in the development of renal interstitial fibrosis [2, 35-37]. TGF- $\beta 1$ may induce excessive accumulation of extracellular matrix, mainly through the following approaches: (1) Smad3-dependent or -independent pathways leading to the accumulation of collagen types I, IV and fibronectin; (2) Renal tubular epithelial-mesenchymal cells transdifferentiation, which is considered to have a direct effect on a myofibroblasts pool during kidney damage, as well as the most critical cell types for matrix accumulation in the renal interstitium.

Renal tubular epithelial-mesenchymal cell transdifferentiation is characterized by the loss of epithelial genetic phenotype and expression of interstitial fibrotic features. Renal interstitial fibroblasts are the major effector cells contributing to EMT in renal interstitial fibrosis, whose proliferation and activation serve the pilot role for ECM. Activated fibroblasts may undergo functional and phenotypic changes and transform into myofibroblasts expressing smooth muscle actins (SMAs). The ability of the myofibroblasts in ECM synthesis would be markedly enhanced and thus continuous accumulation of interstitial matrix would ensue. Therefore, $\alpha$-SMA is one of the most important proteins in the EMT process, 


\section{Cellular Physiology Cell Physiol Biochem 2016;38:1761-1774 \begin{tabular}{ll|l} 
and Biochemistry & $\begin{array}{l}\text { DOI: 10.1159/000443115 } \\
\text { Published online: May 09, } 2016\end{array}$ & $\begin{array}{l}\text { O 2016 The Author(s). Published by S. Karger AG, Basel } \\
\text { www.karger.com/cpb }\end{array}$ \\
\cline { 1 - 2 }
\end{tabular} \\ Zhao et al.: HuangQi Decoction Ameliorates Renal Fibrosis}

Fig. 9. Effect of HuangQi decoction on expressions of T $\beta R I, T \beta R I I, \operatorname{Smad} 2 / 3$, P-Smad2/3, Smad4 and Smad7 in HK2 cells Smad-dependent signaling pathway detected by Western blot. A. Protein expressions after treatment. B-G. Statistical analysis versus A *** $\mathrm{P}<0.001$, compared to Sham group; $\# \mathrm{P}<0.05, \quad \# \# \mathrm{P}<0.01$, \#\#\# $<0.001$, compared to UUO group. $n=3-5$.
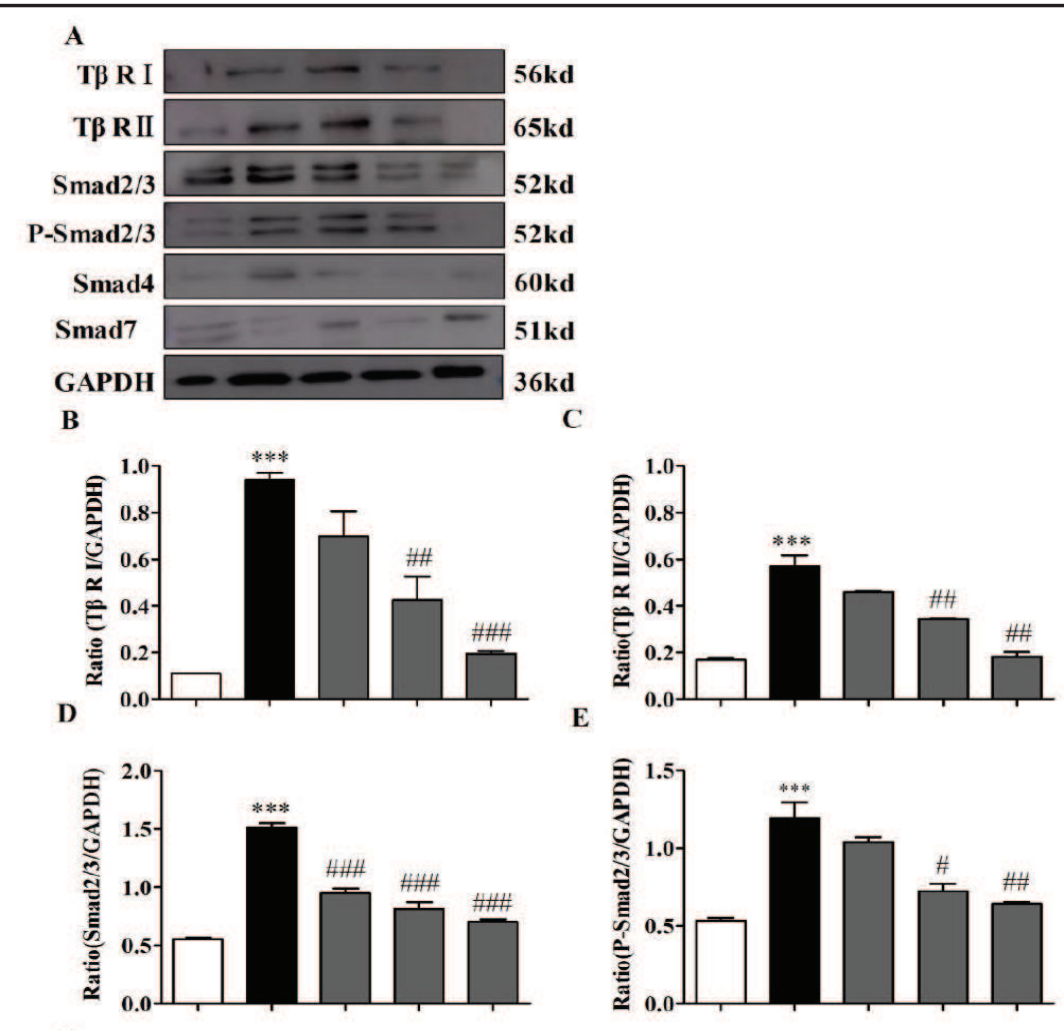

F

G
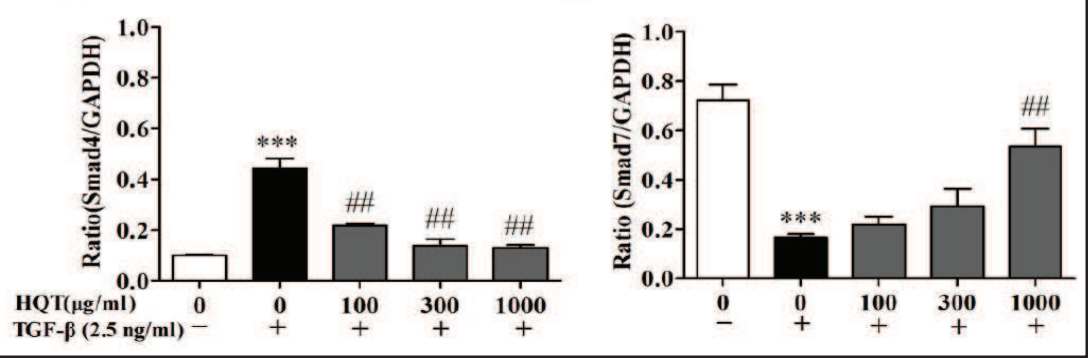

and its expression in activated EMT would be substantially increased [38, 39]. In animal experiments, we observed increased $\alpha$-SMA expression in the obstructed kidneys of UUO model mice using immunohistochemistry, RT-PCR and Western blot; $\alpha$-SMA expression was also significantly increased in cell experiments when HK2 cells were stimulated by TGF- $\beta 1$, suggesting a close association between the development of EMT and renal fibrosis. Collagen is a major component of ECM and under normal conditions the synthesis and degradation of collagen are in a dynamic balance. In addition, we have observed increased expressions of Collagen I, III, IV protein in the obstructed kidney tissue of mice models and HK2 cells in both in vitro and in vivo experiments, suggesting the involvement of EMT increased renal extracellular matrix accumulation. After HuangQi decoction was given, decreased Collagen I, III, IV protein levels were observed. This experiment proved that HuangQi decoction could alleviate EMT and extracellular matrix accumulation by inhibiting Collagen I, III, IV protein expression in a certain extent, and thereby improve renal interstitial fibrosis.

Smad-dependent signaling pathway is considered the most classic signaling pathway in TGF- $\beta 1$-induced fibrosis $[21,40,41]$. Smad2/3 levels would be higher than normal in patients with chronic kidney disease as well as animal models [42-44]. Compromised Smad3 gene in renal tubular epithelial cells would reduce Ang II-induced matrix production [45]. Smad3 gene knockout was also proved to be able to reduce the Ang II-induced matrix production and improve renal fibrosis $[46,47]$. In this experiment, we observed significantly 


\section{Cellular Physiology Cell Physiol Biochem 2016;38:1761-1774 \begin{tabular}{ll|l} 
and B: 10.1159/000443115 & $\begin{array}{l}\text { @ 2016 The Author(s). Published by S. Karger AG, Basel } \\
\text { www.karger.com/cpb }\end{array}$ \\
\hline
\end{tabular} \\ Zhao et al.: HuangQi Decoction Ameliorates Renal Fibrosis}

increased Smad2/3 expression in the obstructed kidney tissues of UUO mice through immunohistochemistry, RT-PCR and Western blot, which was reversed dose-dependently after treatment with HuangQi decoction. TGF- $\beta 1$-induced Smad2/3 expression elevation in HK2 cells was also significantly reduced by high dose of HuangQi decoction. Same changes were found in the level of P-Smad2/3, phosphorylation product of Smad2/3. Smad7 is one type of inhibitory Smad protein, whose expression in normal renal tissue is mainly located in the glomeruli and cortical tubular epithelial cells, with only a small amount in medullary tubules. Smad7 serves as an autoregulative negative feedback signal in TGF- $\beta 1$ signaling, with the ability to adjust TGF- $\beta 1$ signal intensity and duration. Intracellularly, endogenous Smad7 prevents the phosphorylation of R-Smads and thereby inhibiting the transcription of target genes by competitive binding with TGF- $\beta 1$. Meanwhile, Smad7 promote the degradation and ubiquitination of the receptor and thus reducing the reactivity of the TGF- $\beta$ signal $[48,49]$. While in the nucleus, Smad7 can inhibit gene transcription by reducing histone acetylation, thereby blocking the formation of the functional TGF- $\beta$-induced Smad-DNA complex. In this experiment, we found that HuangQi decoction can increase TGF- $\beta 1$-induced Smad7 expression in the obstructed kidney tissue in UUO mice and HK2 cells, thus playing a renal protective role in renal interstitial fibrosis. This experiment also proved that HuangQi decoction could improve renal interstitial fibrosis by affecting the TGF- $\beta /$ Smad signaling pathway and inhibiting EMT and the consequent extracellular matrix accumulation.

\section{Conclusion}

In this study, we observed a dose-dependent improvement of renal interstitial fibrosis in unilateral ureteral obstruction mice models by HuangQi decoction. Both in vivo and cell experiments found that the decoction could downregulate the TGF- $\beta /$ Smad signaling pathway, inhibit EMT, and reduce cell accumulation of extracellular matrix, thereby delaying the progression of renal interstitial fibrosis.

\section{Acknowledgements}

This work was supported by the National Natural Science Foundation of China (81473480, 81403235); Construct Program of the Key Discipline of State Administration of Traditional Chinese Medicine of the People's Republic of China; Leading Academic Discipline Project of State Administration of Traditional Chinese Medicine of China, Talent Project of Integrative Medicine of Shanghai Municipal Health Bureau (ZYSNXD012-RCZXY); Key Medical Discipline Project of Shanghai Municipal Health Bureau (ZK2015A18); Independent Innovation Research Fund of Putuo District Science and Technology Committee (2012PTKW002) and Putuo Hospital Fund (2013SR123I).

\section{Disclosure Statement}

No.

\section{References}

1 Ix JH, Biggs ML, Mukamal K, Djousse L, Siscovick D, Tracy R, Katz R, Delaney JA, Chaves P, Rifkin DE, Hughes-Austin JM, Garimella PS, Sarnak MJ, Shlipak MG, Kizer JR: Urine Collagen Fragments and CKD Progression-The Cardiovascular Health Study. J Am Soc Nephrol 2015;26:2494-2503.

2 Han WQ, Zhu Q, Hu J, Li PL, Zhang F, Li N: Hypoxia-inducible factor prolyl-hydroxylase-2 mediates transforming growth factor beta 1-induced epithelial-mesenchymal transition in renal tubular cells. Biochim Biophys Acta 2013;1833:1454-1462.

3 Eckardt KU, Alper SL, Antignac C, Bleyer AJ, Chauveau D, Dahan K, Deltas C, Hosking A, Kmoch S, Rampoldi L, Wiesener M, Wolf MT, Devuyst O: Autosomal dominant tubulointerstitial kidney disease: diagnosis, classification, and management--A KDIGO consensus report. Kidney Int 2015;88:676-683. 


\section{Cellular Physiology Cell Physiol Biochem 2016;38:1761-1774 \begin{tabular}{ll|l}
\hline DOI: 10.1159/000443115 & () 2016 The Author(s). Published by S. Karger AG, Basel
\end{tabular} and Biochemistry Published online: May 09, 2016 www.karger.com/cpb}

4 Sun S, Sun W, Xia L, Liu L, Du R, He L, Li R, Wang H, Huang C: The T-box transcription factor Brachyury promotes renal interstitial fibrosis by repressing E-cadherin expression. Cell Commun Signal 2014;12:76.

5 Feger M, Alesutan I, Castor T, Mia S, Musculus K, Voelkl J, Lang F: Inhibitory effect of NH4Cl treatment on renal Tgfss1 signaling following unilateral ureteral obstruction. Cell Physiol Biochem 2015;37:955-964.

6 Jiang MQ, Wang L, Cao AL, Zhao J, Chen X, Wang YM, Wang H, Peng W: HuangQi Decoction Improves Renal Tubulointerstitial Fibrosis in Mice by Inhibiting the Up-Regulation of Wnt/beta-Catenin Signaling Pathway. Cell Physiol Biochem 2015;36:655-669.

7 Debelle FD, Nortier JL, De Prez EG, Garbar CH, Vienne AR, Salmon IJ, Deschodt-Lanckman MM, Vanherweghem JL: Aristolochic acids induce chronic renal failure with interstitial fibrosis in salt-depleted rats. J Am Soc Nephrol 2002;13:431-436.

8 Mizuguchi Y, Miyajima A, Kosaka T, Asano T, Asano T, Hayakawa M: Atorvastatin ameliorates renal tissue damage in unilateral ureteral obstruction. J Urol 2004;172:2456-2459.

9 Yuan A, Lee Y, Choi U, Moeckel G, Karihaloo A: Chemokine receptor Cxcr4 contributes to kidney fibrosis via multiple effectors. Am J Physiol Renal Physiol 2015;308:F459-472.

10 Mani H, Zander DS: Immunohistochemistry: applications to the evaluation of lung and pleural neoplasms: part 2. Chest 2012;142:1324-1333.

11 Mani H, Zander DS: Immunohistochemistry: applications to the evaluation of lung and pleural neoplasms: part 1. Chest 2012;142:1316-1323.

12 Tan CY, Weier Q Zhang Y, Cox AJ, Kelly DJ, Langham RG: Thioredoxin-interacting protein: a potential therapeutic target for treatment of progressive fibrosis in diabetic nephropathy. Nephron 2015;129:109127.

13 Mao S, Yan B, Zhang J: Association of transforming growth factor-beta1 polymorphisms with the risk of chronic kidney diseases. Ren Fail 2015;37:304-311.

14 Zhang M, Guo Y, Fu H, Hu S, Pan J, Wang Y, Cheng J, Song J, Yu Q, Zhang S, Xu JF, Pei G, Xiang X, Yang P, Wang CY: Chop deficiency prevents UUO-induced renal fibrosis by attenuating fibrotic signals originated from Hmgb1/TLR4/NFkappaB/IL-1beta signaling. Cell Death Dis 2015;6:e1847.

15 Cheng H, Bo Y, Shen W, Tan J, Jia Z, Xu C, Li F: Leonurine ameliorates kidney fibrosis via suppressing TGFbeta and NF-kappaB signaling pathway in UUO mice. Int Immunopharmacol 2015;25:406-415.

16 Racca MA, Novoa PA, Rodriguez I, Della Vedova AB, Pellizas CG, Demarchi M, Donadio AC: Renal dysfunction and intragraft proMMP9 activity in renal transplant recipients with interstitial fibrosis and tubular atrophy. Transpl Int 2015;28:71-78.

17 Antoine MH, Debelle F, Piccirilli J, El Kaddouri F, Decleves AE, De Prez E, Husson C, Mies F, Bourgeade MF, Nortier JL: Human bone morphogenetic protein-7 does not counteract aristolochic acid-induced renal toxicity. J Appl Toxicol 2015;35:1520-1530.

18 Tateishi Y, Osada-Oka M, Tanaka M, Shiota M, Izumi Y, Ishimura E, Motoyama K, Inaba M, Miura K: Myeloid HIF-1 attenuates the progression of renal fibrosis in murine obstructive nephropathy. J Pharmacol Sci 2015;127:181-189.

19 Wang Y, Wang D, Wu J, Wang B, Wang L, Gao X, Huang H, Ma H: Cinnabar induces renal inflammation and fibrogenesis in rats. Biomed Res Int 2015;2015:280958.

20 Wei FN, Chen ZL, Yang HF, Han L, Ding HM, Deng SG, Ou RM, Ou AH, Liang YF, Hu ZH, Wang J, Yang XH, Yang NZ: Effect of Sanqi Oral Liquid on the expressions of CD4(+), CD8(+) and CD68(+) cells in 5/6 nephrectomized rats with chronic renal failure. Chin J Integr Med 2013;19:589-595.

21 Wei MG, Sun W, Xiong PH, Shao JD: Antifibrotic effect of the Chinese herbs Modified Danggui Buxue Decoction on adriamycin-induced nephropathy in rats. Chin J Integr Med 2012;18:591-598.

22 Wang L, Chi YF, Yuan ZT, Zhou WC, Yin PH, Zhang XM, Peng W: Astragaloside IV inhibits the up-regulation of Wnt/beta-catenin signaling in rats with unilateral ureteral obstruction. Cell Physiol Biochem 2014;33:1316-1328.

23 Wang L, Chi YF, Yuan ZT, Zhou WC, Yin PH, Zhang XM, Peng W, Cai H: Astragaloside IV inhibits renal tubulointerstitial fibrosis by blocking TGF-beta/Smad signaling pathway in vivo and in vitro. Exp Biol Med (Maywood) 2014;239:1310-1324.

24 Zhao J, Wang L, Cao AL, Jiang MQ, Chen X, Peng W: Renal tubulointerstitial fibrosis:A review in animal models. J Integr Nephrol \& Androl 2015;75-80.

25 Zhao YY, Lei P, Chen DQ, Feng YL, Bai X: Renal metabolic profiling of early renal injury and renoprotective effects of Poria cocos epidermis using UPLC Q-TOF/HSMS/MSE. J Pharm Biomed Anal 2013;81-82:202209.

26 Zhao YY, Li HT, Feng YL, Bai X, Lin RC: Urinary metabonomic study of the surface layer of Poria cocos as an effective treatment for chronic renal injury in rats. J Ethnopharmacol 2013;148:403-410. 


\section{Cellular Physiology Cell Physiol Biochem 2016;38:1761-1774 and Biochemistry DOI: 10.1159/000443115 $\quad$ () 2016 The Author(s). Published by S. Karger AG, Basel and Biochemistry Published online: May 09, 2016 www.karger.com/cpb}

27 Ding YF, Peng YR, Li J, Shen H, Shen MQ Fang TH: Gualou Xiebai Decoction prevents myocardial fibrosis by blocking TGF-beta/Smad signalling. J Pharm Pharmacol 2013;65:1373-1381.

28 Seo CS, Kim TW, Kim YJ, Park SR, Ha H, Shin HK, Jung JY: Trichosanthes kirilowii ameliorates cisplatininduced nephrotoxicity in both in vitro and in vivo. Nat Prod Res 2015;29:554-557.

29 Lu HJ, Tzeng TF, Liou SS, Da Lin S, Wu MC, Liu IM: Ruscogenin ameliorates diabetic nephropathy by its antiinflammatory and anti-fibrotic effects in streptozotocin-induced diabetic rat. BMC Complement Altern Med 2014;14:110.

30 Chun JN, Kim SY, Park EJ, Kwon EJ, Bae DJ, Kim IS, Kim HK, Park JK, Lee SW, Park HH, So I, Jeon JH: Schisandrin B suppresses TGFbeta1-induced stress fiber formation by inhibiting myosin light chain phosphorylation. J Ethnopharmacol 2014;152:364-371.

31 Park EJ, Chun JN, Kim SH, Kim CY, Lee HJ, Kim HK, Park JK, Lee SW, So I, Jeon JH: Schisandrin B suppresses TGFbeta1 signaling by inhibiting Smad2/3 and MAPK pathways. Biochem Pharmacol 2012;83:378-384.

32 Li J, Kang SW, Kim JL, Sung HY, Kwun IS, Kang YH: Isoliquiritigenin entails blockade of TGF-beta1SMAD signaling for retarding high glucose-induced mesangial matrix accumulation. J Agric Food Chem 2010;58:3205-3212.

33 Qiu H, Fan W, Fu P, Zuo C, Feng P, Liu F, Zhou L, Chen F, Zhong H, Liang Y, Shi M: General acteoside of Rehmanniae leaves in the treatment of primary chronic glomerulonephritis: a randomized controlled trial. Afr J Tradit Complement Altern Med 2013;10:109-115.

34 Yokozawa T, Kim HY, Yamabe N: Amelioration of diabetic nephropathy by dried Rehmanniae Radix (Di Huang) extract. Am J Chin Med 2004;32:829-839.

35 Chang J, Wang H, Wang X, Zhao Y, Zhao D, Wang C, Li Y, Yang Z, Lu S, Zeng Q, Zimmerman J, Shi Q, Wang Y, Yang Y: Molecular mechanisms of Polyphyllin I-induced apoptosis and reversal of the epithelialmesenchymal transition in human osteosarcoma cells. J Ethnopharmacol 2015;170:117-127.

36 Lamouille S, Xu J, Derynck R: Molecular mechanisms of epithelial-mesenchymal transition. Nat Rev Mol Cell Biol 2014;15:178-196.

37 Garcia-Sanchez 0, Sancho-Martinez SM, Lopez-Novoa JM, Lopez-Hernandez FJ: Activation of the ALK-5 Pathway is not per se Sufficient for the Antiproliferative Effect of TGF-beta1 on Renal Tubule Epithelial Cells. Cell Physiol Biochem 2015;37:1231-1239.

38 Tang X, Rong G, Bu Y, Zhang S, Zhang M, Zhang J, Liang X: Advanced oxidation protein products induce hypertrophy and epithelial-to-mesenchymal transition in human proximal tubular cells through induction of endoplasmic reticulum stress. Cell Physiol Biochem 2015;35:816-828.

39 Li WJ, Yang CL, Chow KC, Kuo TW: Hexavalent chromium induces expression of mesenchymal and stem cell markers in renal epithelial cells. Mol Carcinog 2016;55:182-192.

40 Overstreet JM, Samarakoon R, Meldrum KK, Higgins PJ: Redox control of p53 in the transcriptional regulation of TGF-beta1 target genes through SMAD cooperativity. Cell Signal 2014;26:1427-1436.

41 Samarakoon R, Overstreet JM, Higgins PJ: TGF-beta signaling in tissue fibrosis: redox controls, target genes and therapeutic opportunities. Cell Signal 2013;25:264-268.

42 Xiao Z, Zhang J, Peng X, Dong Y, Jia L, Li H, Du J: The Notch gamma-secretase inhibitor ameliorates kidney fibrosis via inhibition of TGF-beta/Smad2/3 signaling pathway activation. Int J Biochem Cell Biol 2014;55:65-71.

43 Kim D, Lee AS, Jung YJ, Yang KH, Lee S, Park SK, Kim W, Kang KP: Tamoxifen ameliorates renal tubulointerstitial fibrosis by modulation of estrogen receptor alpha-mediated transforming growth factorbeta1/Smad signaling pathway. Nephrol Dial Transplant 2014;29:2043-2053.

44 de Oliveira FA, Sanders-Pinheiro H: Low-level laser therapy decreases renal interstitial fibrosis. Photomed Laser Surg 2013;31:507-508.

45 Yang F, Huang XR, Chung AC, Hou CC, Lai KN, Lan HY: Essential role for Smad3 in angiotensin II-induced tubular epithelial-mesenchymal transition. J Pathol 2010;221:390-401.

46 Chung AC, Zhang H, Kong YZ, Tan JJ, Huang XR, Kopp JB, Lan HY: Advanced glycation end-products induce tubular CTGF via TGF-beta-independent Smad3 signaling. J Am Soc Nephrol 2010;21:249-260.

47 Yang F, Chung AC, Huang XR, Lan HY: Angiotensin II induces connective tissue growth factor and collagen I expression via transforming growth factor-beta-dependent and -independent Smad pathways: the role of Smad3. Hypertension 2009;54:877-884.

48 Zhang J, Zhang X, Xie F, Zhang Z, van Dam H, Zhang L, Zhou F: The regulation of TGF-beta/SMAD signaling by protein deubiquitination. Protein Cell 2014;5:503-517.

49 Xie F, Zhang Z, van Dam H, Zhang L, Zhou F: Regulation of TGF-beta Superfamily Signaling by SMAD MonoUbiquitination. Cells 2014;3:981-993. 